\title{
The influence of superplasticizer and shrinkage reducing admixture type on air-content and related properties of HPSCC
}

\author{
Beata Łaźniewska-Piekarczyk ${ }^{1, *}$ \\ ${ }^{1}$ Silesian University of Technology, Faculty of Building Engineering, Department of Building \\ Processes and Building Physics, Akademicka 5 str., 44-100 Gliwice, Poland
}

\begin{abstract}
Theoretically, high-performance concrete with w/c ratio about 0.30 and $\mathrm{w} / \mathrm{b}$ about 0.28 should have low porosity, low water permeability and high strength. The purpose of this study was to examine the influence of the superplasticizers( with and without air-entraining effect) and shrinkage reducing admixture based on a high molecular weight basis alcohol amount on the air-content, compressive strength, shrink and resistance to water penetration of high-performance self-compacting concrete (HPSCC). The test results have shown that despite the low water content, concrete modified with inadequately selected SP and high amount of SRA has a high porosity and low strength and water permeability. The types of superplasticizers and amount of SRA are significant due to porosity parameters, compressive strength and water-permeability of HPSCC. The water permeability and compressive strength of HPSCC depending on the effects of amount of SRA admixtures on the volume of pores in HPSCC. Moreover, shrinkage of incidental air-entrained concrete, despite its lower endurance, after 28 days of hardening it is smaller than non-aerated concrete.
\end{abstract}

\section{Introduction}

Many concrete properties, although not directly referred to in the EN 206 concrete standard, are specified and used in practice to assess the durability of cement composites. These properties include water resistance, frost resistance, shrinkage, resistance to chemical corrosion. Theoretically, high-strength concrete with w/c $=0.3$ should have low water permeability $[1,2,3]$.

High-performance self-compacting concrete (HPSCC) is concrete that can flow and consolidate under its weight, fill the formwork even in the presence of dense reinforcement, while maintaining homogeneity and without the need for any additional compaction. Recently devoted attention devotes much attention lately also shrinkage reducing admixtures (SRA). An incorrectly chosen modifier system instead of reducing shrinkage the opposite effect can be achieved [3].

The paper presents the development of high-performance self-compacting concrete (HPSCC) with two different types of PCE superplasticizers (with and without air-entertaining

\footnotetext{
* Corresponding author: beata.lazniewska@polsl.pl
} 
effect) and SRA based on a high molecular weight basis alcohol. The study was then carried out on the fresh and hardened properties of different HPSCC at constant water on cement ratio, type and volume of aggregate, and cement paste volume. The main objective of the research is to determine the influence of admixtures on the rheological aspect, air-content in the fresh concrete mixture, porosity characteristics, compressive strength and resistance to water penetration of HPSCC.

\section{Materials and description of the tests}

The experimental investigation was carried out in two phases. In Phase 1, tests were carried out on fresh high-performance self-compacting concrete with a different type of SPs and different amount of SRA based on a high molecular weight basis alcohol. Phase 2 investigated the properties of hardened HPSCC.

\subsection{Examined materials}

A CEM I 42,5 R cement type was used. Chemical and physical properties of cement are shown in Table 1. The chemical and physical properties of silica fume (SF) are shown in Table 2. Local natural sand, fine and eight-millimetre maximum size gravel aggregates, were used in the concrete mixture, respectively. Table 3 presents the properties of sand and coarse aggregate.

The properties of SPs admixtures are presented in Table 3. A shrinkage reducer admixture (SRA) was based on a high molecular weight basis alcohol.

Table 1. The chemical and physical properties of CEM I $42.5 \mathrm{R}$.

\begin{tabular}{|c|c|c|c|c|c|c|c|c|c|c|c|}
\hline \multicolumn{7}{|c|}{ Chemical analyses \% } & \multirow{3}{*}{\begin{tabular}{|l|} 
Specific \\
surface \\
Blaine \\
$\mathrm{cm}^{2} / \mathrm{g}$
\end{tabular}} & \multirow{3}{*}{\begin{tabular}{|c} 
Specific \\
gravity \\
g/cm
\end{tabular}} & \multirow{3}{*}{$\begin{array}{l}\text { Compressive } \\
\text { strength } \\
\text { MPa }\end{array}$} & \multirow{2}{*}{\multicolumn{2}{|c|}{$\begin{array}{l}\text { Setting time, } \\
\text { Vicat test, min }\end{array}$}} \\
\hline $\mathrm{SiO}_{2}$ & $\mathrm{CaO}$ & $\mathrm{Al}_{2} \mathrm{O}_{3}$ & $\mathrm{Fe}_{2} \mathrm{O}_{3}$ & $\mathrm{MgO}$ & $\mathrm{Na}_{2} \mathrm{Oe}$ & $\mathrm{SO}_{3}$ & & & & & \\
\hline & & & & & & & & & & $\begin{array}{l}\text { Initial } \\
\text { setting }\end{array}$ & $\begin{array}{l}\text { Final } \\
\text { setting }\end{array}$ \\
\hline 1.61 & 64.41 & 4.46 & 2.24 & 1.25 & 0.4 & 3.1 & 3830 & 3.1 & 69.3 & 175 & - \\
\hline
\end{tabular}

Table 2. The chemical and physical properties of silica fume.

\begin{tabular}{|c|c|c|c|c|c|c|c|c|}
\hline \multicolumn{7}{|c|}{ Chemical analyses \% } & Specific surface, \\
$\mathrm{m}^{2} / \mathbf{k g}$
\end{tabular}

Table 3. The properties of PCE superplasticizers.

\begin{tabular}{|l|l|l|}
\hline \multicolumn{1}{|c|}{ Property } & \multicolumn{1}{c|}{ SP1 } & \multicolumn{1}{c|}{ SP2 } \\
\hline Main base & polycarboxyl ether & polycarboxyl ether \\
\hline $\begin{array}{l}\text { Specific gravity at } 20^{\circ} \mathrm{C}, \\
\mathrm{g} / \mathrm{cm}^{3}\end{array}$ & $1.07 \pm 0.02$ & $1.05 \pm 0.02$ \\
\hline pH-value at $20^{\circ} \mathrm{C}$ & $6.5 \pm 1.0$ & $6.5 \pm 1.5$ \\
\hline Chloride ion content, \% mas. & $\leq 0.1$ & 1.3 \\
\hline $\begin{array}{l}\text { Alkali content }\left(\mathrm{Na}_{2} \mathrm{O}_{\text {eqiv. }}\right), \% \\
\text { mass }\end{array}$ & 1.5 & 1.3 \\
\hline
\end{tabular}

High performance self-compacting concrete mixtures (Table $4 \div$ Table 6) were made to study the effect of the interaction of SP and SRA admixtures on the investigated properties of HPSCC. The proportion of cement, silica fume, water, coarse aggregate and sand was kept constant (Table 4). 
The following admixtures were used (Table 5 and Table 6): SP1 (with air-entraining side effect), SP2 (without air-entraining side effect), SRA1, SRA2 and SRA3.

The concrete was produced in a horizontal pan mixer with a capacity of $0.070 \mathrm{~m}^{3}$. The sand and coarse aggregate were first mixed for $1 \mathrm{~min}$. Then, cement and fly ash were added with the water, after mixing for $10 \mathrm{~min}$, the SP was added. Finally, remaining admixtures (according to Table 5 and Table 6) were added and mixed for an additional $3 \mathrm{~min}$.

Table 4. The components of HPSCC.

\begin{tabular}{|c|c|c|c|c|c|c|}
\hline $\begin{array}{l}\text { CEM I } \\
42,5 R\end{array}$ & $\begin{array}{l}\text { Silica } \\
\text { fume }\end{array}$ & Sand $0 / 2 \mathrm{~mm}$ & Gravel 0/8 mm & Volume of paste & \multirow[t]{2}{*}{$\mathbf{w} / \mathbf{c}$} & \multirow[t]{2}{*}{$\mathbf{w} / \mathbf{b}$} \\
\hline \multicolumn{4}{|c|}{$\mathrm{kg} / \mathrm{m}^{3}$} & $\%$ & & \\
\hline 581.0 & 65.0 & 710.1 & 887.6 & 40.0 & 0.31 & 0.28 \\
\hline
\end{tabular}

Table 5. The dosage of SP by of total binder weight, $\%$.

\begin{tabular}{|l|l|l|}
\hline Series & SP1 & SP2 \\
\hline S1 & 3.75 & - \\
\hline S2 & - & 3.34 \\
\hline
\end{tabular}

Table 6. The dosage of SP and SRA by weight of total binder, $\%$.

\begin{tabular}{|l|l|l|l|}
\hline Series & SP1 & SP2 & SRA \\
\hline S1SR1 & 3.58 & - & 1,0 \\
\hline S1SR2 & 3.67 & - & 2,5 \\
\hline S1SR3 & 3.60 & - & 5,0 \\
\hline S2SR1 & - & 3.32 & 1,0 \\
\hline S2SR2 & - & 3.22 & 2,5 \\
\hline S2SR3 & - & 3.35 & 5,0 \\
\hline
\end{tabular}

\subsection{The methodology of HPSCC properties test}

In order to measure the shrinkage of HPSCC after 28 days of maturation of the stain in a climatic chamber an Amsler apparatus was used and 3 samples of each concrete with dimensions of $10 \times 10 \times 50 \mathrm{~cm}$ with pegs embedded in the foreheads.

The slump flow test (EN 12350-8:2010[5]) was used to evaluate the free deformability and flowability of HPSCC. Slump flow value represented the mean diameter (measured in two perpendicular directions) of concrete after lifting the standard slump cone. The upper and lower limits of slump-flow classes (SF) are the following (EN 12350-8:2010): SF1slump flow from 50 to $650 \mathrm{~mm}$, SF2- slump flow from 660 to $750 \mathrm{~mm}$, SF3- slump flow from 760 to $850 \mathrm{~mm}$. While the upper and lower limits of viscosity classes (VS) are the following (EN 12350-8:2010): VS1 - $\mathrm{T}_{500}$ less than or equal to $2 \mathrm{sec}$., VS2 - $\mathrm{T}_{500}$ greater than $2 \mathrm{sec}$. The air content in fresh HPSCC was measured by the pressure method, according to EN 12350-7[6].

The temperature and relative humidity carrying concrete specimens were respectively $20^{\circ} \mathrm{C}$ and $100 \%$ (in water). After 28 days carrying, the tests of concrete were conducted to determine the compressive strength and water penetration under the pressure of HPSCC. The compressive strength and water penetration under the pressure of HPSCC were established using standard test methods: the compressive strength on cube specimens according to EN 12350-3 [7], the water penetration under pressure on cube specimens according to EN 123908 [8]. Strength and depth of penetration of water under pressure was made on cubic samples with a side of $150 \mathrm{~mm}$. In the tests carried out, the W8 water resistance level was adopted, 
which corresponds to the impact of an $80 \mathrm{~m}$ water column. The air content in hardened HPSCC was investigated according to EN-480-11 [9].

\section{Test results and its discussion}

\subsection{The research results of fresh mortars and concrete}

Test results of the test of properties of the fresh HPSCC are summarized in Table 7. The analysis of the test results suggests that the type of PCE SP influences the air-content in the fresh high-performance self-compacting concrete. According to the publications $[10,11]$ polycarboxylate superplasticizers usually have an air-entraining effect. Moreover, the aircontent in concrete mixes was increased by SRA admixtures. This conclusion complies with the research results of publication [12]. The publications research results indicated that SRA admixtures increase the overall porosity of the concrete, but significantly reduce its share of large pores (300-1000 nm). SRA admixtures are often used together with superpasticizing; however, it requires careful selection, especially SPs type and amount of SRA.

Table 7 compares the own deformations HPSCC concrete with SP and SP and with SRA. The observed swelling of by-entrained concrete as in the publication [13], the greater the greater the air content. Shrinkage of incidental air-entrained concrete despite its lower endurance it is smaller than non-aerated concrete. Clarification of the problem of contraction air-entrained concrete requires further extensive research.

Table 7. Properties of fresh HPSCC without and with SRA.

\begin{tabular}{|l|l|l|l|l|}
\hline Series & SF, $\mathbf{m m}$ & T $_{\mathbf{5 0 0}}$, sec. & $\mathbf{A}_{\mathbf{c}}, \boldsymbol{\%}$ & $\begin{array}{l}\text { Shrinkage } \\
\text { (deformation) } \\
\text { value }\end{array}$ \\
\hline S1SR1 & 672 & 4 & 3.8 & $550 * 10^{-6}$ \\
\hline S1SR2 & 669 & 4 & 4.1 & $530^{-6} 10^{-6}$ \\
\hline S1SR3 & 667 & 4 & 4.8 & $440^{-6} 10^{-6}$ \\
\hline S2SR1 & 675 & 4 & 2.9 & $330^{*} 10^{-6}$ \\
\hline S2SR2 & 676 & 3 & 3.5 & $560 * 10^{-6}$ \\
\hline S2SR3 & 674 & 3 & 3.9 & $540^{-6} 10^{-6}$ \\
\hline S1 & 675 & 4 & 3.6 & $560 * 10^{-6}$ \\
\hline S2 & 677 & 4 & 2.6 & $310^{-6} 10^{-6}$ \\
\hline
\end{tabular}

\subsection{The research results of hardened HPSCC}

The research results of the properties of hardened HPSCC are summarized in Table 8. The research results analyzed in Table 8 lead to the conclusion that the type of SP and amount of SRA are significant because of the HPSCC air-content, strength and water penetration depth.

Table 8. The research results of the compressive strength and water penetration of HPSCC.

\begin{tabular}{|l|l|l|l|}
\hline Series & $\mathbf{f}_{\mathbf{c m}}, \mathbf{N} / \mathbf{m m}^{\mathbf{2}}$ & $\begin{array}{l}\text { Water penetration } \\
\text { depth, } \mathbf{m m}\end{array}$ & $\begin{array}{l}\text { Air content in } \\
\text { concrete, \% }\end{array}$ \\
\hline S1 & 89.5 & 38.0 & 3.2 \\
\hline S1SR1 & 77.2 & 69.3 & 3.9 \\
\hline S1SR2 & 72.7 & 84.7 & 4.2 \\
\hline S1SR3 & 68.0 & 98.0 & 2.5 \\
\hline
\end{tabular}




\begin{tabular}{|l|l|l|l|}
\hline S2 & 92.9 & 25.4 & 3.2 \\
\hline S2SR1 & 84.3 & 45.6 & 4.0 \\
\hline S2SR2 & 79.9 & 63.3 & 3.3 \\
\hline S2SR3 & 75.3 & 86.7 & 2.4 \\
\hline
\end{tabular}

The research results of water penetration of HPSCC are presented in Table 8. The resistance of HPSCC to water penetration depends on SP type and amount of SRA. The type of PCE superplasticizer is significant for water permeability. The superplasticizer SP1 excessively increasing the air content in concrete, as a consequence, causes deterioration of its water permeability. SRA increase the water penetration depth of HPSCC, as was shown in Fig. 1.

a)
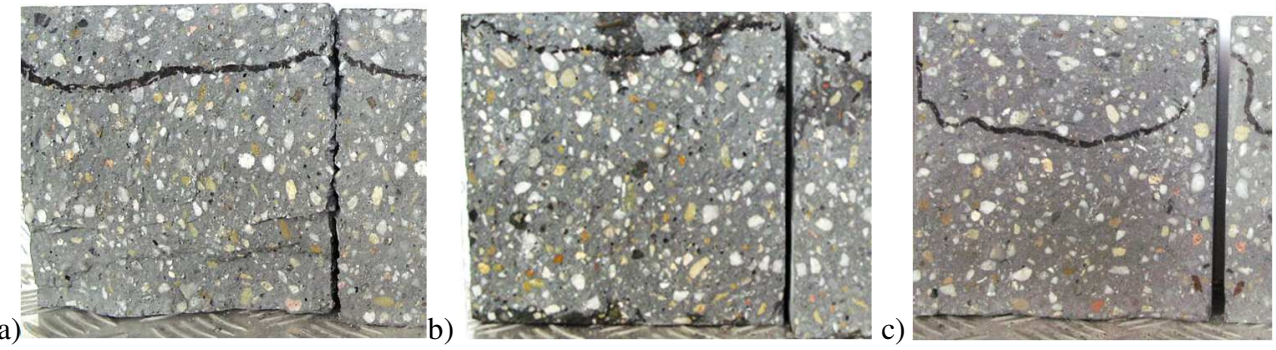

Fig. 1. The research results of water-permeability of S1(a), S2 (b) and S1SR1(c).

Standard EN 13877-2 "Concrete pavements. Part 2: Functional requirements for concrete pavements" [14] recommends testing the depth of water penetration under pressure to determine the resistance of concrete to the penetration of gasoline, oil and other chemical substances, the permissible depth of water penetration should not exceed $30 \mathrm{~mm}$. After the injection of water under pressure, the sample is cut, and the depth of water penetration determined on the cross-sectional surface of the sample is measured. The measurement result determines the water permeability of concrete. According to the General Technical Specification for structural concrete in road construction, concrete in structural elements exposed to the effects of a chemically aggressive environment should show resistance to water penetration under pressure (test according to PN-EN 12390-8 "Concrete tests - Part 8: Depth of water penetration under pressure). The requirements for cement and concrete, given the requirements of the General Technical Specification (OST) [15]. Surface made of cement concrete [15], recently updated by the General Directorate for National Roads and Motorways (in Polish: GDDKiA). The document has the status of an annexe to the Regulation of the General Director of National Roads and Motorways from $7^{\text {th }}$ June 2018, which in practice opens a new chapter in the design and construction of roads with concrete pavement., the maximum penetration depth should not exceed: $60 \mathrm{~mm}$ in the XA1 exposure class, $50 \mathrm{~mm}$ in the XA2 exposure class, $40 \mathrm{~mm}$ in the XA3 exposure class. Concrete in structural components exposed to corrosion due to chloride in exposure classes XD3 and XS3 should have a maximum penetration depth of not more than $40 \mathrm{~mm}$. Analyzing the results, the data in Table 8 show that only a concretes without SRA would meet the requirements of standards $[14,15,16]$.

The role of the SRA in increasing the deflocculation of the mixture and consequently, it causes a better distribution of the pore system. Further, the higher porosity may be the result of a reduction in the rate of cement hydration and consequently, a delayed setting and a slower strength development $[16,17,19,20]$. The research results presented in Table 8 indicated that increasing dosages of SRA reduced the compressive strength, similarly like in publication [17]. In the publication [18] was indicated that the decrease of shrinkage due to SRA is attributed to the reduction of the surface tension of the pore water moreover, the addition of the SRA causes another physical effect on the porous. The decrease in surface tension of 
water is directly connected with air-content in concrete. Shrinkage reducers, based on high molecular weight processing alcohol, were developed in the mid-1980s in Japan, and they were introduced into common use at the beginning of the $90 \mathrm{~s}$. The admixtures from this group are non-ionic surfactants. It strengthens one bond water in the mixture and the guarantee that the drying process of the cement composite is delayed. As relationships Surface-active admixtures of this type lower the mains voltage of water, thus reducing the pressure in the capillary pores, which according to Wittmann [21] shows the formula (1):

$$
P=\frac{2 \gamma}{r}
$$

where:

$P$ - capillary pressure,

$\gamma$ - surface tension of the filling solution the pores,

$r$ - meniscus radius.

The negative effect of using admixtures from this group is the possibility of reducing the strength of the composite by $5-8 \%$ as a result of air entrainment of the mixture [21,22], which is also proved in this article.It may be deduced from the data that the total porosity value is larger in specimens containing $1 \%$ SRA; the same tendency was also obtained with water porosimetry in publication [12]. The paste pore structure influences drying behaviour and also affect spore pressure development in the paste. However, as demonstrated in another publication [22], the age of the sample is not insignificant due to its permeability. In this publication, the water-absorption behaviour of cement pastes $(\mathrm{w} / \mathrm{c}=0.30)$ containing varying concentrations (i.e., 0, 0.2, and 5\%) of a shrinkage-reducing admixture (SRA) was measured. A decrease in both the depth of water penetration and the rate of water absorption was observed with increasing specimen maturity and SRA admixture concentration. Strength, resistivity and chloride diffusion are measured at 330 days in publication [23]. Results showed that different type of SRAs induced similar effects and that mix composition plays an essential role in the SRA performance. This effect reduces the drying shrinkage reducing the interplanar distances in the structure CSH [24,25]. Organic shrinkage reducers, thanks to increasing the cohesion of the mixture and the toughness of the mixing water, have an impact also the shape and size of the crystals of the hydration products cement. Ettringite crystals are prismatic in shape needles, not typical hexagonal plates.

The test results have shown, that even though HPSCC has a low w/c $=0.31 \mathrm{ratio}$, too high amount SRA admixtures can destroy the careful selection of the remaining concrete ingredients to ensure its high abrasiveness and low water permeability. Some types of PCE superplasticizers cause excessive aeration, and, as a result, reduce the strength of concrete and deteriorate durability, associated with permeability. On the other hand, adding SRA to concrete should be preceded by an indirect assessment of its effect on porosity and the associated strength and water permeability of concrete. An improperly selected SRA admixture, and especially an excess of it, causes a significant deterioration in the durability and permeability of HPSCC. However, there is also information in the publication [27] that the compressive and flexural strength values of SCC samples with SRA and additional chemical additives were compared to the respective values of samples without additives for this purpose. Thus, the problem of the influence of SRA admixtures needs futural investigations. 


\section{Conclusions}

In the range of investigation of the HPSCC, used admixtures and received research results, it was indicated that the examined admixtures significantly affect the properties of fresh and hardened HPSCC:

- Shrinkage of incidental air-entrained concrete, despite its lower endurance, after 28 days of hardening it is smaller than non-aerated concrete. Clarification of the problem of contraction air-entrained concrete requires further extensive research.

- SRA based on a high molecular weight basis alcohol and SP excessively increasing the air content in concrete cause deterioration of compressive strength and water permeability.

\section{References}

1. Y. Zhao, F. Wittmann, P. Zhang, P. Wang, T. Zhao, Restoration of Buildings and Monuments (De Gruyter, 2014).

2. T. C. Powers, J. Amer. Ceram. Society, 41, 1-6 (1958)

3. Y. Zhuqing, N. Chenxin, T. Mingliang, S. Xiaodong, Constr. Build. Mater. 175, 458466 (2018)

4. J. Mora-Ruacho, R. Gettu, A. Aguado, Cem. Concr. Res. 39, 141-146 (2009)

5. EN $12350-8$ (2010)

6. EN 12350-7 (2009)

7. EN 12390-3 (2002)

8. EN $12390-8(2001)$

9. EN 480-11 (2005)

10. S. Hanehara, K. Yamada, Cem. Concr. Res. 21, 175-195 (2008)

11. B. Łaźniewska-Piekarczyk, Constr. Build. Mater., 31, 310-319 (2012)

12. J. Saliba, E. Rozière, F. Grondin, A. Loukili, , Cem. Concr. Compos. 33, 209-217 (2011)

13. W. Piasta, H. Sikora, Odkształcenia własne betonów napwietrzonych, Przegląd Budowlany, 4, 28-31, (2009) (in Polish)

14. EN 13877-2 (2013)

15. https://www.gddkia.gov.pl/frontend/web/userfiles/articles/d/dokumentytechniczne_8162/D - 05.03.04.pdf (in Polish)

16. Regulation of the Minister of Transport and Maritime Economy Dz. U. No 63, poz. 735 (2000), (in Polish)

17. C. V. Nguyen, P. S. Mangat, G. Jones, 3rd International Conference on Building Materials and Construction (February, Vietnam 2018)

18. A. B. Ribeiro, A. Gonçalves, A. Carrajola, Mater. Struct. 39, 179-187 (2006)

19. F. Rajabipour, G. Sant. J. Weiss, Cem. Concr. Res. 38, 606-615 (2008)

20. K. J. Folliard, N. S. Berke. Cem. Concr. Res. 27(9), 1357-1364 (1997)

21. G. Sant, A. Eberhardt, D. Bentz, J. Weiss, J. Mater. Civil Eng. 22(3)(2010).

22. M. Suzuki., M. Tanimura., R. Sato, Fourth International Seminar on Self-desiccation and Its Importance in Concrete Technology (June, Gaithersburg 2005)

23. L. Czarnecki, P. Łukowski, Cement Lime Concrete, 6 (2003)

24. L. Maia, H. Figueira, S. Nunes, M. Azenha, J. Figueiras, Constr. Build. Mater. 35, 304$312(2012)$ 
25. C. Maltese, C. Pistolesi, A. Lolli, A. Bravo, T. Crulli, D. Salvioni, Cem. Concr. Res. 35, 2244-2251 (2005)

26. F. Wittmann., On the action of capillary pressure in fresh concrete, Cem. Concr. Res. 6, 49-56 (1976)

27. K. Ilker, D. İlhami, E. Şule, S. Ozer, 12th International Congress on Advances in Civil Engineering, (İstanbul, 2016) 